\title{
Free vibration of semi-rigid connected Reddy-Bickford piles embedded in elastic soil
}

\author{
YUSUF YESILCE* and HIKMET H CATAL \\ Dokuz Eylul University, Civil Engineering Department, Engineering Faculty, \\ 35160, Buca, Izmir, Turkey \\ e-mail: yusuf.yesilce@deu.edu.tr
}

MS received 14 February 2008; revised 28 April 2008

\begin{abstract}
The literature on free vibration analysis of Bernoulli-Euler and Timoshenko piles embedded in elastic soil is plenty, but that of Reddy-Bickford piles partially embedded in elastic soil with/without axial force effect is fewer. The soil that the pile partially embedded in is idealized by Winkler model and is assumed to be two-layered. The pile part above the soil is called the first region and the parts embedded in the soil are called the second and the third region, respectively. It is assumed that the behaviour of the material is linear-elastic, that axial force along the pile length to be constant and the upper end of the pile that is semi-rigid supported against rotation is modelled by an elastic spring. The governing differential equations of motion of the rectangular pile in free vibration are derived using Hamilton's principle and Winkler hypothesis. The terms are found directly from the solutions of the differential equations that describe the deformations of the cross-section according to the high-order theory. The models have six degrees of freedom at the two ends, one transverse displacement and two rotations, and the end forces are a shear force and two end moments. Natural frequencies of the pile are calculated using transfer matrix and the secant method for non-trivial solution of linear homogeneous system of equations obtained due to values of axial forces acting on the pile, total and embedded lengths of the pile, the linear-elastic rotational restraining stiffness at the upper end of the pile and to the boundary conditions of the pile. Two different boundary conditions are considered in the study. For the first boundary condition, the pile's end at the first region is semi-rigid connected and not restricted for horizontal displacement and the end at the third region is free and for the second boundary condition, the pile's end at the first region is semi-rigid connected and restricted for horizontal displacement and the end at the third region is fixed supported. The calculated natural frequencies of semi-rigid connected Reddy-Bickford pile embedded in elastic soil are given in tables and compared with results of Timoshenko pile model.
\end{abstract}

Keywords. Axial force effect; free vibration; Reddy-Bickford pile; semi-rigid connected; transfer matrix.

*For correspondence 


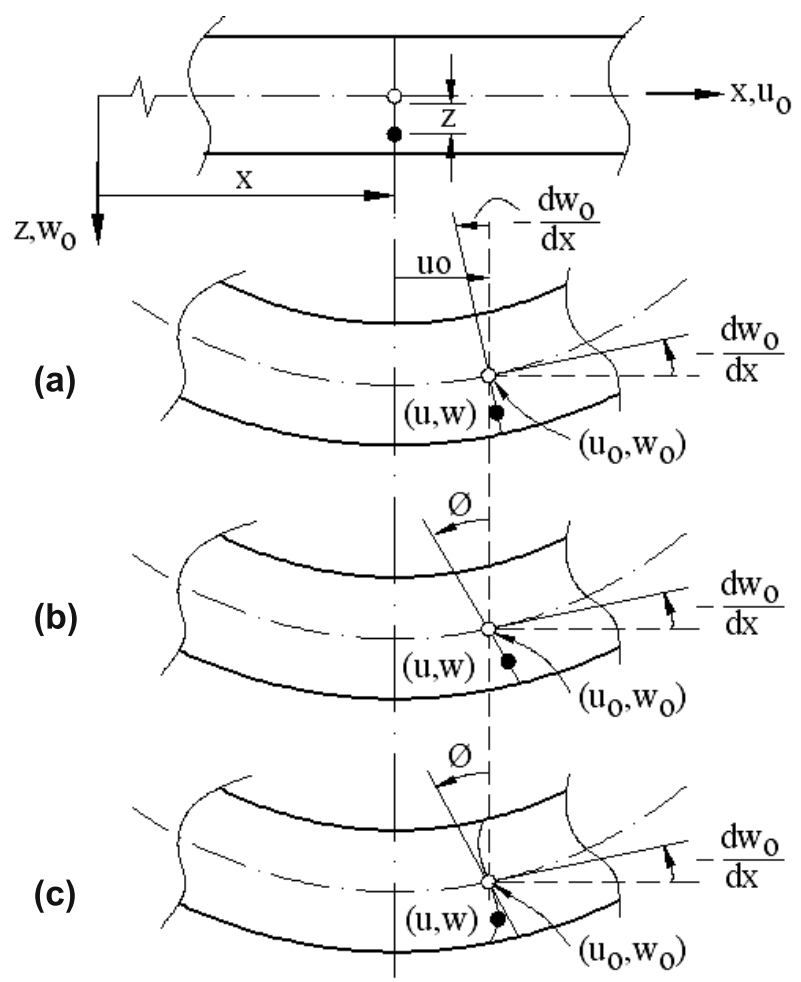

Figure 1. Cross-section displacements in different beam theories (Wang et al 2000) (a) Bernoulli-Euler Beam Theory (BET); (b) Timoshenko Beam Theory (TBT); (c) ReddyBickford Beam Theory (RBT).

\section{Introduction}

The analysis of the piles embedded in elastic soil is similar to the analysis of beams on elastic foundations.

The analysis of beams has been performed over the years mostly using Bernoulli-Euler beam theory (BET). The classical Bernoulli-Euler beam is well studied for slender beams, where the transverse shear deformation can be safely disregarded. This theory is based on the assumption that plane sections of the cross-section remain plane and perpendicular to the beam axis. The cross-sectional displacements are shown in (figure 1a), and expressed as

$$
\begin{aligned}
& u(x, z, t)=-z \cdot \frac{\partial w_{0}(x, t)}{\partial x} \\
& w(x, z, t)=w_{0}(x, t),
\end{aligned}
$$

where $w_{0}(x, t)$ is the lateral displacement of the beam neutral axis, $z$ is the distance from the beam neutral axis.

For moderately thick beams Bernoulli-Euler beam theory can be modified in order to take into account the transverse shear effect in a simplified way. For example, the well-known Timoshenko beam theory (TBT) predicts a uniform shear distribution, so necessitating the use of a so-called shear factor (Cowper 1966, Gruttmann \& Wagner 2001, Murthy 1970). The cross-sectional displacements of Timoshenko beam theory are shown in (figure 1b) and the 
equations for Timoshenko beam theory which relaxes the restriction on the angle of shearing deformations are;

$$
\begin{aligned}
u(x, z, t) & =z \cdot \phi(x, t) \\
w(x, z, t) & =w_{0}(x, t),
\end{aligned}
$$

where $\phi(x, t)$ represents the rotation of a normal to the axis of the beam. Han et al (1999) presented a comprehensive study of Bernoulli-Euler, Rayleigh, Shear and Timoshenko beam theories.

The real shear deformation distribution is not uniform along the depth of the beam, so that Timoshenko beam theory is not recommended for composite beams, where the accurate determination of the shear stresses is required. Especially, it was found that the Timoshenko shear deformation theory has some major numerical problems such as locking in the numerical analysis for composite materials. The other problem was the need to supply an artificially derived shear correction factor. Although some remedies were devised, as a result, several higher-order theories have emerged. These theories, with small variations, are due to several authors relax the restriction on the warping of the cross-section and allow variation in the longitudinal direction of the beam which is cubic (Bickford 1982, Heyliger \& Reddy 1988, Levinson 1981, Wang et al 2000).

In this paper, Reddy-Bickford beam theory (RBT) is used, which seems a good compromise between accuracy and simplicity (Bickford 1982, Wang et al 2000). The cross-sectional displacements of Reddy-Bickford beam theory are shown in (figure 1c) and according to Reddy-Bickford beam theory, the displacements of the rectangular beam can be written as (Wang et al 2000, Reddy 2002, Reddy 2007)

$$
\begin{aligned}
& u(x, z, t)=z \cdot \phi(x, t)-\alpha \cdot z^{3} \cdot\left[\phi(x, t)+\frac{\partial w(x, t)}{\partial x}\right], \\
& w(x, z, t)=w_{0}(x, t)
\end{aligned}
$$

where $\alpha=\frac{4}{3 \cdot h^{2}} ; h$ is height of the beam.

Bernoulli-Euler beam theory does not consider the shear stress in the cross-section and the associated strains. Thus, the shear angle is taken as zero through the height of the cross-section. Timoshenko beam theory assumes constant shear stress and shear strain in the cross-section. On the top and bottom edges of the beam the free surface condition is thus violated. The use of a shear correction factor, in various forms including the effect of Poisson's ratio, does not correct this fault of the theory, but rather artificially adjusts the solutions to match the static or dynamic behaviour of the beam. Reddy-Bickford beam theory and the other high-order theories remedy this physical mismatch at the free edges by assuming variable shear strain and shear stress along the height of the cross-section. Then there is no need for the shear correction factor. The high-order theory is more exact and represents much better physics of the problem. It results in a sixth-order theory compared to the fourth-order of the other lessaccurate theories. This yields a six-degree-of-freedom element with six end forces, a shear force, bending moment and a high-order moment, at the two ends of the beam element.

The determination of the natural frequencies is crucial in the dynamic analysis of piles that are partially embedded in the soil. Previously, it was widely assumed that the upper ends of piles used to support offshore structures, marine and harbor structures or bridges are fully rigidly connected. In reality, these connections are neither fully rigid nor flexible. They fall between fully rigid and flexible connections, depending on the cross-sectional and material 
properties of the piles. A more reasonable way is to treat them as semi-rigid connections in the structural analysis.

The analysis of a partially supported pile is similar to that of a beam that is elastically supported. Previously, numerous researchers studied the behaviour of beams supported by elastic foundations (Hetenyi 1955). Doyle \& Pavlovic (1982) solved the partial differential equation for free vibration of beams partially attached to elastic foundation using variable separating method and neglecting axial force and shear effects. Boroomand \& Kaynia (1991) studied dynamic analysis of pile-soil-pile interaction for vertical piles in a homogeneous soil by using a Fourier expansion of variables. Aviles \& Sanchez-Sesma (1983) studied the usefulness of a row of rigid piles as an isolating barrier for elastic waves. They formulated the problem as one of multiple scattering and diffraction. Aviles \& Sanchez-Sesma (1988) presented a theoretical analysis to solve the problem of foundation isolation, using a row of elastic piles as an isolating barrier for elastic waves. Liao \& Sangrey (1978) employed an acoustic model for the use of rows of piles as passive isolation barriers to reduce ground vibrations. West \& Mafi (1984) solved the partial differential equation for free vibration of an elastic beam on elastic foundation that is subjected to axial force by using initial value method. Yokoyama (1991) studied the free vibration motion of Timoshenko beam on two-parameters elastic foundation. Esmailzadeh \& Ohadi (2000) investigated vibration and stability analysis of non-uniform Timoshenko beams under axial and distributed tangential loads. Catal (2002) calculated natural frequencies and relative stiffness of the pile for non-trivial solution of linear homogeneous system of equations obtained due to the values of axial forces acting on the pile, the shape factors, and the boundary conditions of the pile with both ends free and both ends simply supported by using Timoshenko beam theory and transfer matrix. Further, he proceeded to determine the natural frequencies of Timoshenko piles partially embedded in the soil, but semi-rigidly connected at the upper ends, using the method of initial values (Catal 2006). Lin \& Chang (2005) studied free vibration analysis of multi-span Timoshenko beam with an arbitrary number of flexible constraints by transfer matrix method. Demirdag \& Catal (2007) investigated spectral analysis of semi-rigid supported single storey frames modelled as Timoshenko column with attached mass. Demirdag (2008) studied elastically-supported Timoshenko column with attached masses is under consideration to obtain its free vibration natural frequencies using two different algorithm; transfer matrix method and finite element method. Yesilce \& Catal (2008) calculated normalized natural frequencies of Timoshenko pile due to the different values of axial force using transfer matrix and considering rotatory inertia.

\section{The mathematical model and formulation}

A rectangular pile partially embedded in the soil whose upper end is semi-rigid connected against rotation is presented in (figure 2). The pile part above the soil is called the first region and the parts embedded in the soil are called the second and the third region, respectively.

Using Hamilton's principle and Eqs. (5) and (6); the equations of motion can be written for each region as (Wang et al 2000, Eisenberger 2003):

$$
\begin{gathered}
-\frac{68}{105} \cdot E I_{x} \cdot \frac{\partial^{2} \phi_{j}\left(x_{j}, t\right)}{\partial x_{j}^{2}}+\frac{16}{105} \cdot E I_{x} \cdot \frac{\partial^{3} w_{j}\left(x_{j}, t\right)}{\partial x_{j}^{3}}+\frac{8}{15} \cdot A G \\
\cdot\left[\phi_{j}\left(x_{j}, t\right)+\frac{\partial w_{j}\left(x_{j}, t\right)}{\partial x_{j}}\right]=0 \quad\left(0 \leq x_{j} \leq L_{j}\right) \quad(j=1,2,3)
\end{gathered}
$$




$$
\begin{aligned}
& -m \cdot \frac{\partial^{2} w_{1}\left(x_{1}, t\right)}{\partial t^{2}}+\frac{8}{15} \cdot A G \cdot\left[\frac{\partial \phi_{1}\left(x_{1}, t\right)}{\partial x_{1}}+\frac{\partial^{2} w_{1}\left(x_{1}, t\right)}{\partial x_{1}^{2}}\right]+\frac{16}{105} \cdot E I_{x} \\
& \cdot \frac{\partial^{3} \phi_{1}\left(x_{1}, t\right)}{\partial x_{1}^{3}}-\frac{1}{21} \cdot E I_{x} \cdot \frac{\partial^{4} w_{1}\left(x_{1}, t\right)}{\partial x_{1}^{4}}-N \cdot \frac{\partial^{2} w_{1}\left(x_{1}, t\right)}{\partial x_{1}^{2}}=0\left(0 \leq x_{1} \leq L_{1}\right) \\
& -m \cdot \frac{\partial^{2} w_{k}\left(x_{k}, t\right)}{\partial t^{2}}+\frac{8}{15} \cdot A G \cdot\left[\frac{\partial \phi_{k}\left(x_{k}, t\right)}{\partial x_{k}}+\frac{\partial^{2} w_{k}\left(x_{k}, t\right)}{\partial x_{k}^{2}}\right]+\frac{16}{105} \cdot E I_{x} \cdot \frac{\partial^{3} \phi_{k}\left(x_{k}, t\right)}{\partial x_{k}^{3}} \\
& -\frac{1}{21} \cdot E I_{x} \cdot \frac{\partial^{4} w_{k}\left(x_{k}, t\right)}{\partial x_{k}^{4}}-C_{S(k-1)} \cdot w_{k}\left(x_{k}, t\right)-N \cdot \frac{\partial^{2} w_{k}\left(x_{k}, t\right)}{\partial x_{k}^{2}}=0\left(0 \leq x_{k} \leq L_{k}\right)(k=2,3),
\end{aligned}
$$

where $w_{j}\left(x_{j}, t\right)$ is displacement function for $j^{\text {th }}$ region of the pile, $\phi_{j}\left(x_{j}, t\right)$ represents the rotation of a normal to the axis for $j^{\text {th }}$ region of the pile, $m$ is mass per unit length of the pile, $L_{1}$ is pile length above the soil, $L_{2}$ is pile length embedded in the second region, $L_{3}$ is pile length embedded in the third region, $L$ is total length of the pile, $N$ is the constant axial compressive force, $A$ is the cross-section area, $I_{x}$ is moment of inertia, $E, G$ are Young's modulus and shear modulus of the pile, $C_{S 1}=C_{R 1} . b$ and $C_{S 2}=C_{R 2} . b$ in which $C_{R 1}, C_{R 2}$

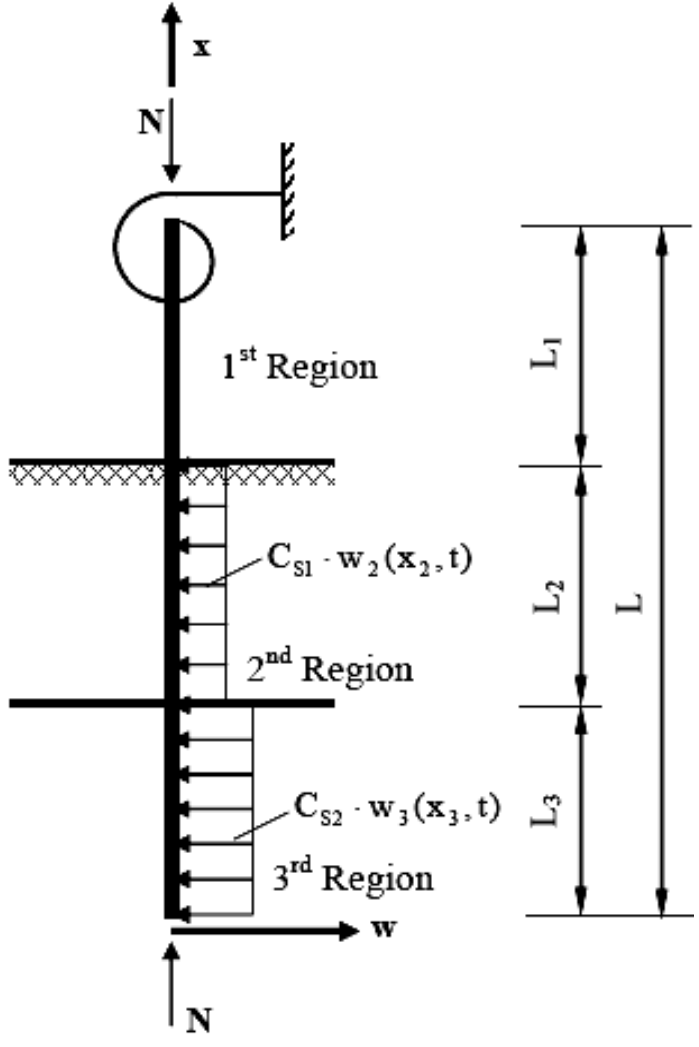

Figure 2. Pile partially embedded in the elastic soil. 
are the modulus of subgrade reaction for the second and the third regions, respectively and $b$ is width of the pile, $x_{1}, x_{2}$ and $x_{3}$ are pile positions for the first, the second and the third regions, $t$ is time variable.

Assuming that the motion is harmonic we substitute for $w_{j}\left(z_{j}, t\right)$ and $\phi_{j}\left(r_{j}, t\right)$ the following:

$$
\begin{aligned}
& w_{j}\left(z_{j}, t\right)=w_{j}\left(z_{j}\right) \cdot \sin (\omega \cdot t) \\
& \phi_{j}\left(z_{j}, t\right)=\phi_{j}\left(z_{j}\right) \cdot \sin (\omega \cdot t) \quad(j=1,2,3)
\end{aligned}
$$

and obtain a system of two coupled ordinary equation for each region as:

$$
\begin{aligned}
& -\frac{68}{105} \cdot \frac{E I_{x}}{L^{2}} \cdot \frac{d^{2} \phi_{j}\left(z_{j}\right)}{d z_{j}^{2}}+\frac{16}{105} \cdot \frac{E I_{x}}{L^{3}} \cdot \frac{d^{3} w_{j}\left(z_{j}\right)}{d z_{j}^{3}}+\frac{8}{15} \cdot A G \\
& \cdot\left[\phi_{j}\left(z_{j}\right)+\frac{1}{L} \cdot \frac{d w_{j}\left(z_{j}\right)}{d z_{j}}\right]=0 \quad(j=1,2,3) \\
& m \cdot \omega^{2} \cdot w_{1}\left(z_{1}\right)+\frac{8}{15} \cdot \frac{A G}{L} \cdot\left[\frac{d \phi_{1}\left(z_{1}\right)}{d z_{1}}+\frac{1}{L} \cdot \frac{d^{2} w_{1}\left(z_{1}\right)}{d z_{1}^{2}}\right]+\frac{16}{105} \cdot \frac{E I_{x}}{L^{3}} \\
& \cdot \frac{d^{3} \phi_{1}\left(z_{1}\right)}{d z_{1}^{3}}-\frac{1}{21} \cdot \frac{E I_{x}}{L^{4}} \cdot \frac{d^{4} w_{1}\left(z_{1}\right)}{d z_{1}^{4}}-N_{r} \cdot \frac{\pi^{2} \cdot E I_{x}}{L^{4}} \cdot \frac{d^{2} w_{1}\left(z_{1}\right)}{d z_{1}^{2}}=0 \\
& m \cdot \omega^{2} \cdot w_{k}\left(z_{k}\right)+\frac{8}{15} \cdot \frac{A G}{L} \cdot\left[\frac{d \phi_{k}\left(z_{k}\right)}{d z_{k}}+\frac{1}{L} \cdot \frac{d^{2} w_{k}\left(z_{k}\right)}{d z_{k}^{2}}\right]+\frac{16}{105} \\
& \cdot \frac{E I_{x}}{L^{3}} \cdot \frac{d^{3} \phi_{k}\left(z_{k}\right)}{d z_{k}^{3}}-\frac{1}{21} \cdot \frac{E I_{x}}{L^{4}} \cdot \frac{d^{4} w_{k}\left(z_{k}\right)}{d z_{k}^{4}}-C_{S(k-1)} \cdot w_{k}\left(z_{k}\right)-N_{r} \\
& \cdot \frac{\pi^{2} \cdot E I_{x}}{L^{4}} \cdot \frac{d^{2} w_{k}\left(z_{k}\right)}{d z_{k}^{2}}=0 \quad(k=2,3),
\end{aligned}
$$

where $z=\frac{x}{L}$, dimensionless position parameter; $N_{r}=\frac{N \cdot L^{2}}{\pi^{2} \cdot E I_{x}}$, non-dimensionalized multiplication factor for the axial compressive force and $\omega$ is natural frequency of the pile.

It is assumed that the solution is

$$
\begin{aligned}
& w_{j}\left(z_{j}\right)=C_{j} \cdot e^{i \cdot s_{j} \cdot z_{j}} \\
& \phi_{j}\left(z_{j}\right)=P_{j} \cdot e^{i \cdot s_{j} \cdot z_{j}} \quad(j=1,2,3)
\end{aligned}
$$

and substituting Eqs. (15) and (16) into Eqs. (12), (13) and (14) results in

$$
\begin{aligned}
& \left(\frac{8}{15} \cdot A G+\frac{68}{105} \cdot \frac{E I_{x}}{L^{2}} \cdot s_{j}^{2}\right) \cdot P_{j} \\
& \quad+\left(\frac{8}{15} \cdot \frac{A G}{L} \cdot s_{j} \cdot i-\frac{16}{105} \cdot \frac{E I_{x}}{L^{3}} \cdot s_{j}^{3} \cdot i\right) \cdot C_{j}=0 \quad(j=1,2,3)
\end{aligned}
$$




$$
\begin{aligned}
& \left(\frac{8}{15} \cdot \frac{A G}{L} \cdot s_{1} \cdot i-\frac{16}{105} \cdot \frac{E I_{x}}{L^{3}} \cdot s_{1}^{3} \cdot i\right) \cdot P_{1} \\
& \quad+\left(m \cdot \omega^{2}-\frac{8}{15} \cdot \frac{A G}{L^{2}} \cdot s_{1}^{2}-\frac{1}{21} \cdot \frac{E I_{x}}{L^{4}} \cdot s_{1}^{4}+N_{r} \cdot \frac{\pi^{2} \cdot E I_{x}}{L^{4}} \cdot s_{1}^{2}\right) \cdot C_{1}=0 \\
& \left(\frac{8}{15} \cdot \frac{A G}{L} \cdot s_{k} \cdot i-\frac{16}{105} \cdot \frac{E I_{x}}{L^{3}} \cdot s_{k}^{3} \cdot i\right) \cdot P_{k} \\
& \quad+\left(m \cdot \omega^{2}-\frac{8}{15} \cdot \frac{A G}{L^{2}} \cdot s_{k}^{2}-\frac{1}{21} \cdot \frac{E I_{x}}{L^{4}} \cdot s_{k}^{4}-C_{S(k-1)}+N_{r} \cdot \frac{\pi^{2} \cdot E I_{x}}{L^{4}} \cdot s_{k}^{2}\right) \\
& \quad C_{k}=0 \quad(k=2,3),
\end{aligned}
$$

where $i=\sqrt{-1}$.

Eqs. (17), (18) and (19) can be written in matrix form for the two unknowns $P_{j}$ and $C_{j}$ and the non-trivial solution will be obtained when the determinant of the coefficient matrix will be zero for each region, i.e.

$$
\begin{aligned}
& {\left[-\frac{4}{525} \cdot \frac{\left(E I_{x}\right)^{2}}{L^{6}}\right] \cdot s_{1}^{6}+\left[\frac{68}{105} \cdot \frac{N_{r} \cdot \pi^{2} \cdot\left(E I_{x}\right)^{2}}{L^{6}}-\frac{8}{15} \cdot \frac{A G \cdot E I_{x}}{L^{4}}\right] \cdot s_{1}^{4}} \\
& \quad+\left(\frac{68}{105} \cdot \frac{E I_{x}}{L^{2}} \cdot m \cdot \omega^{2}+\frac{8}{15} \cdot \frac{N_{r} \cdot \pi^{2} \cdot E I_{x} \cdot A G}{L^{4}}\right) \cdot s_{1}^{2} \\
& \quad+\frac{8}{15} \cdot A G \cdot m \cdot \omega^{2}=0 \\
& {\left[-\frac{4}{525} \cdot \frac{\left(E I_{x}\right)^{2}}{L^{6}}\right] \cdot s_{k}^{6}+\left[\frac{68}{105} \cdot \frac{N_{r} \cdot \pi^{2} \cdot\left(E I_{x}\right)^{2}}{L^{6}}-\frac{8}{15} \cdot \frac{A G \cdot E I_{x}}{L^{4}}\right] \cdot s_{k}^{4}} \\
& \quad+\left(\frac{68}{105} \cdot \frac{E I_{x}}{L^{2}} \cdot\left(m \cdot \omega^{2}-C_{S(k-1)}\right)+\frac{8}{15} \cdot \frac{N_{r} \cdot \pi^{2} \cdot E I_{x} \cdot A G}{L^{4}}\right) \cdot s_{k}^{2} \\
& \quad+\frac{8}{15} \cdot A G \cdot\left(m \cdot \omega^{2}-C_{S(k-1)}\right)=0 .
\end{aligned}
$$

Thus, we have a sixth-order equation with the unknowns for each region, resulting in six values and the general solution for each region can be written as:

$$
\begin{aligned}
w_{j}\left(z_{j}, t\right)= & {\left[C_{j 1} \cdot e^{i \cdot s_{j 1} \cdot z_{j}}+C_{j 2} \cdot e^{i \cdot s_{j 2} \cdot z_{j}}+C_{j 3} \cdot e^{i \cdot s_{j 3} \cdot z_{j}}+C_{j 4} \cdot e^{i \cdot s_{j 4} \cdot z_{j}}\right.} \\
& \left.+C_{j 5} \cdot e^{i \cdot s_{j 5} \cdot z_{j}}+C_{j 6} \cdot e^{i \cdot s_{j 6} \cdot z_{j}}\right] \cdot \sin (\omega \cdot t) \\
\phi_{j}\left(z_{j}, t\right)= & {\left[P_{j 1} \cdot e^{i \cdot s_{j 1} \cdot z_{j}}+P_{j 2} \cdot e^{i \cdot s_{j 2} \cdot z_{j}}+P_{j 3} \cdot e^{i \cdot s_{j 3} \cdot z_{j}}+P_{j 4} \cdot e^{i \cdot s_{j 4} \cdot z_{j}}\right.} \\
& \left.+P_{j 5} \cdot e^{i \cdot s_{j 5} \cdot z_{j}}+P_{j 6} \cdot e^{i \cdot s_{j 6} \cdot z_{j}}\right] \cdot \sin (\omega \cdot t) \quad(j=1,2,3) .
\end{aligned}
$$


The thirty-six constants, $C_{j 1}, \ldots, C_{j 6}$ and $P_{j 1}, \ldots, P_{j 6}$, will be found from Eqs. (17), (18), (19) and boundary conditions.

For each region, the expression for bending rotation $w_{j}^{\prime}\left(z_{j}, t\right)$ is given by

$$
w_{j}^{\prime}\left(z_{j}, t\right)=\frac{1}{L} \cdot \frac{d w_{j}\left(z_{j}\right)}{d z_{j}} \cdot \sin (\omega \cdot t) \quad(j=1,2,3) .
$$

For each region, the shear force function $Q_{j}\left(z_{j}, t\right)$ can be obtained by using Eqs. (22) and (23) as:

$$
\begin{aligned}
Q_{j}\left(z_{j}, t\right)= & -\frac{8 \cdot A G}{15} \cdot\left(\phi_{j}\left(z_{j}\right)+\frac{1}{L} \cdot \frac{d w_{j}\left(z_{j}\right)}{d z_{j}}\right) \cdot \sin (\omega \cdot t) \\
& +N_{r} \cdot \frac{\pi^{2} \cdot E I_{x}}{L^{3}} \cdot \frac{d w_{j}\left(z_{j}\right)}{d z_{j}} \cdot \sin (\omega \cdot t) \\
& +\frac{E I_{x}}{21 \cdot L^{3}} \cdot \frac{d^{3} w_{j}\left(z_{j}\right)}{d z_{j}^{3}} \cdot \sin (\omega \cdot t) \\
& -\frac{16 \cdot E I_{x}}{105 \cdot L^{2}} \cdot \frac{d^{2} \phi_{j}\left(z_{j}\right)}{d z_{j}^{2}} \cdot \sin (\omega \cdot t) \quad(j=1,2,3) .
\end{aligned}
$$

Similarly, the bending moment function $M_{j}\left(z_{j}, t\right)$ can be obtained by using Eqs. (22) and (23) as:

$$
\begin{aligned}
M_{j}\left(z_{j}, t\right)= & \left(-\frac{E I_{x}}{21 \cdot L^{2}} \cdot \frac{d^{2} w_{j}\left(z_{j}\right)}{d z_{j}^{2}}-N_{r} \cdot \frac{\pi^{2} \cdot E I_{x}}{L^{2}} \cdot w_{j}\left(z_{j}\right)\right. \\
& \left.+\frac{16 \cdot E I_{x}}{105 \cdot L} \cdot \frac{d \phi_{j}\left(z_{j}\right)}{d z_{j}}\right) \cdot \sin (\omega \cdot t) .
\end{aligned}
$$

For each region, the higher-order moment function $M_{h j}\left(z_{j}, t\right)$ can be obtained as:

$M_{h j}\left(z_{j}, t\right)=\left(\frac{16 \cdot E I_{x}}{105 \cdot L^{2}} \cdot \frac{d^{2} w_{j}\left(z_{j}\right)}{d z_{j}^{2}}-\frac{68 \cdot E I_{x}}{105 \cdot L} \cdot \frac{d \phi_{j}\left(z_{j}\right)}{d z_{j}}\right) \cdot \sin (\omega \cdot t) \quad(j=1,2,3)$.

\section{Obtaining the transfer matrices of the pile}

The position for each region is written due to the values of the transverse displacement $w_{j}\left(z_{j}, t\right)$, bending rotation $w_{j}^{\prime}\left(z_{j}, t\right)$, rotation of normal $\phi_{j}\left(z_{j}, t\right)$, shear force $Q_{j}\left(z_{j}, t\right)$, bending moment $M_{h}\left(z_{j}, t\right)$ and higher-order moment function $M_{h j}\left(z_{j}, t\right)$ at the locations of $z_{j}$ and $t$ for Reddy-Bickford pile, as $(j=1,2,3)$ :

$$
\left\langle S_{j}\left(z_{j}, t\right)\right\rangle^{T}=\left\langle w_{j}\left(z_{j}\right) \quad w_{j}^{\prime}\left(z_{j}\right) \quad \phi_{j}\left(z_{j}\right) \quad M_{j}\left(z_{j}\right) \quad M_{h j}\left(z_{j}\right) \quad Q_{j}\left(z_{j}\right)\right\rangle^{T} \cdot \sin (\omega . t),
$$

where $\left\{S_{j}\left(z_{j}, t\right)\right\}$ shows the position vector for each region. 
All terms of the position vector in Eq. (28), is written reducing the $\sin (\omega t)$ terms as:

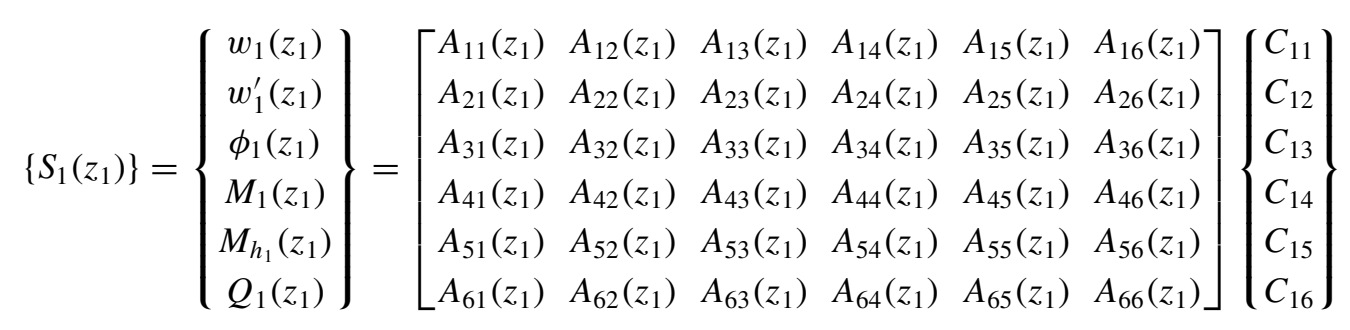

$\left\{S_{2}\left(z_{2}\right)\right\}=\left\{\begin{array}{c}w_{2}\left(z_{2}\right) \\ w_{2}^{\prime}\left(z_{2}\right) \\ \phi_{2}\left(z_{2}\right) \\ M_{2}\left(z_{2}\right) \\ M_{h_{2}}\left(z_{2}\right) \\ Q_{2}\left(z_{2}\right)\end{array}\right\}=\left[\begin{array}{llllll}B_{11}\left(z_{2}\right) & B_{12}\left(z_{2}\right) & B_{13}\left(z_{2}\right) & B_{14}\left(z_{2}\right) & B_{15}\left(z_{2}\right) & B_{16}\left(z_{2}\right) \\ B_{21}\left(z_{2}\right) & B_{22}\left(z_{2}\right) & B_{23}\left(z_{2}\right) & B_{24}\left(z_{2}\right) & B_{25}\left(z_{2}\right) & B_{26}\left(z_{2}\right) \\ B_{31}\left(z_{2}\right) & B_{32}\left(z_{2}\right) & B_{33}\left(z_{2}\right) & B_{34}\left(z_{2}\right) & B_{35}\left(z_{2}\right) & B_{36}\left(z_{2}\right) \\ B_{41}\left(z_{2}\right) & B_{42}\left(z_{2}\right) & B_{43}\left(z_{2}\right) & B_{44}\left(z_{2}\right) & B_{45}\left(z_{2}\right) & B_{46}\left(z_{2}\right) \\ B_{51}\left(z_{2}\right) & B_{52}\left(z_{2}\right) & B_{53}\left(z_{2}\right) & B_{54}\left(z_{2}\right) & B_{55}\left(z_{2}\right) & B_{56}\left(z_{2}\right) \\ B_{61}\left(z_{2}\right) & B_{62}\left(z_{2}\right) & B_{63}\left(z_{2}\right) & B_{64}\left(z_{2}\right) & B_{65}\left(z_{2}\right) & B_{66}\left(z_{2}\right)\end{array}\right]\left\{\begin{array}{l}C_{21} \\ C_{22} \\ C_{23} \\ C_{24} \\ C_{25} \\ C_{26}\end{array}\right\}$

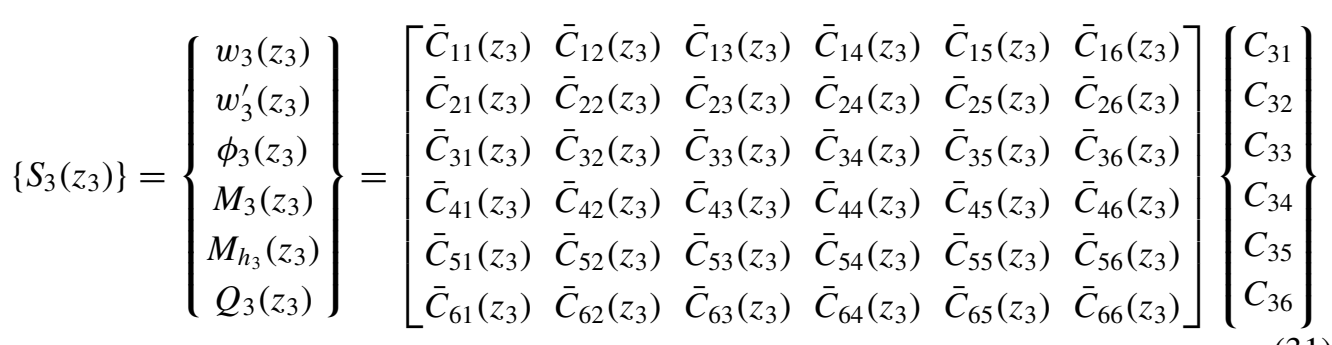

Eqs. (29), (30) and (31) can be written in closed form, as $[(j=1, \ldots, 6),(m=$ $1, \ldots, 6),(n=1, \ldots, 6)]$ :

$$
\begin{aligned}
& \left\{S_{1}\left(z_{1}\right)\right\}=\left[A_{j m}\left(z_{1}\right)\right] \cdot\left\{C_{1 n}\right\} \\
& \left\{S_{2}\left(z_{2}\right)\right\}=\left[B_{j m}\left(z_{2}\right)\right] \cdot\left\{C_{2 n}\right\} \\
& \left\{S_{3}\left(z_{3}\right)\right\}=\left[\bar{C}_{j m}\left(z_{3}\right)\right] \cdot\left\{C_{3 n}\right\} .
\end{aligned}
$$

The coefficient vectors $\left\{C_{1 n}\right\},\left\{C_{2 n}\right\},\left\{C_{3 n}\right\}$ are obtained from Eqs. (32), (33) and (34) for $z_{1}=0, z_{2}=0$ and $z_{3}=0$ with the condition that the matrices $\left[A_{j m}\left(z_{1}\right)\right],\left[B_{j m}\left(z_{2}\right)\right]$ and $\left[\bar{C}_{j m}\left(z_{3}\right)\right]$ are not singular. Substituting these coefficient vectors into the Eqs. (32), (33) and (34) respectively, gives,

$$
\begin{aligned}
& \left\{S_{1}\left(z_{1}\right)\right\}=\left[F_{1}\left(z_{1}\right)\right] \cdot\left\{S_{1}(0)\right\} \\
& \left\{S_{2}\left(z_{2}\right)\right\}=\left[F_{2}\left(z_{2}\right)\right] \cdot\left\{S_{2}(0)\right\} \\
& \left\{S_{3}\left(z_{3}\right)\right\}=\left[F_{3}\left(z_{3}\right)\right] \cdot\left\{S_{3}(0)\right\}
\end{aligned}
$$


where;

$$
\begin{aligned}
& {\left[F_{1}\left(z_{1}\right)\right]=\left[A_{j m}\left(z_{1}\right)\right] \cdot\left[A_{j m}(0)\right]^{-1}} \\
& {\left[F_{2}\left(z_{2}\right)\right]=\left[B_{j m}\left(z_{2}\right)\right] \cdot\left[B_{j m}(0)\right]^{-1}} \\
& {\left[F_{3}\left(z_{3}\right)\right]=\left[\bar{C}_{j m}\left(z_{3}\right)\right] \cdot\left[\bar{C}_{j m}(0)\right]^{-1}}
\end{aligned}
$$

are the transfer matrices for the first, the second and the third regions of the pile, respectively.

The transfer matrices for the three regions can be combined to yield one global transfer matrix using the characteristics of transfer matrix. Thus, the position vector of the pile end at the third region can be related to the position vector of the pile end at the first region as

$$
\begin{aligned}
& \left\{S_{1}\left(z_{1}=1\right)\right\}=\left[F_{1}\left(z_{1}=\frac{L_{1}}{L}\right)\right] \cdot\left[F_{2}\left(z_{2}=\frac{L_{2}}{L}\right)\right] \cdot\left[F_{3}\left(z_{3}=\frac{L_{3}}{L}\right)\right] \cdot\left\{S_{3}\left(z_{3}=0\right)\right\} \\
& \left\{S_{1}\left(z_{1}=1\right)\right\}=[F(z=1)] \cdot\left\{S_{3}\left(z_{3}=0\right)\right\},
\end{aligned}
$$

where $[F(z=1)]$ shows the global transfer matrix that transfers the values of the position vector of the pile end at the third region to the values of the position vector of the pile end at the first region and can be written as:

$$
[F(z=1)]=\left[\begin{array}{llllll}
F_{11} & F_{12} & F_{13} & F_{14} & F_{15} & F_{16} \\
F_{21} & F_{22} & F_{23} & F_{24} & F_{25} & F_{26} \\
F_{31} & F_{32} & F_{33} & F_{34} & F_{35} & F_{36} \\
F_{41} & F_{42} & F_{43} & F_{44} & F_{45} & F_{46} \\
F_{51} & F_{52} & F_{53} & F_{54} & F_{55} & F_{56} \\
F_{61} & F_{62} & F_{63} & F_{64} & F_{65} & F_{66}
\end{array}\right],
$$

where the term $F_{j m}$ shows the terms of the global transfer matrix $[F(z=1)]$.

\section{Obtaining natural frequencies for semi-rigid connected pile}

The behaviour of the pile end that is semi-rigid supported against rotation at the first region is modelled by an elastic spring. The rotational spring rigidities are related with fixity factor that is defined as below (Monforton \& Wu 1963):

$$
f=\frac{1}{1+\frac{3 \cdot E I_{x}}{C_{\theta} \cdot L}},
$$

where $C_{\theta}$ is the rotational restraining stiffness at the upper end of the pile in the first region.

Bending moment function at semi-rigid connected end is written as a linear function of rotational restraining stiffness and bending rotation as (Wang et al 2000):

$$
M_{1}\left(z_{1}=\frac{L_{1}}{L}\right)=-C_{\theta} \cdot \phi_{1}\left(z_{1}=\frac{L_{1}}{L}\right),
$$




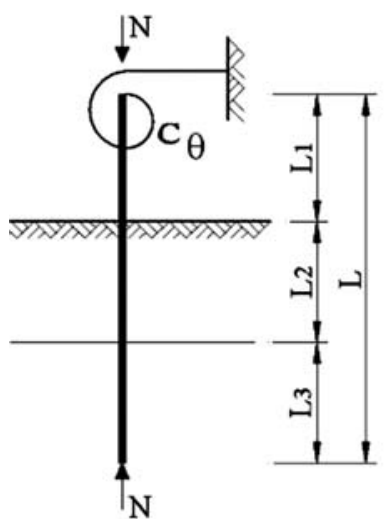

(a)

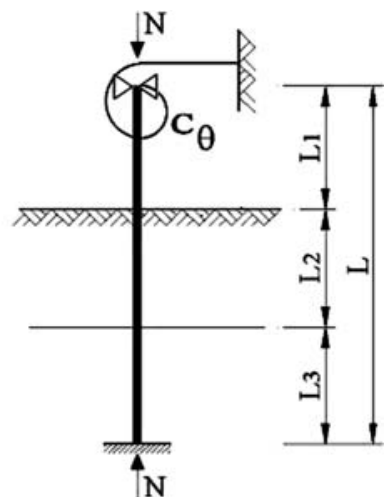

(b)

Figure 3. (a) Pile whose end at the first region is semi-rigid connected and not restricted for horizontal displacement and the end at the third region is free (The first model). (b) Pile whose end at the first region is semi-rigid connected and restricted for horizontal displacement and the end at the third region is fixed supported (The second model).

where $M_{1}\left(z_{1}=\frac{L_{1}}{L}\right)$ and $\phi_{1}\left(z_{1}=\frac{L_{1}}{L}\right)$ are the bending moment and the rotation of normal for the first region.

Similarly, high-order moment function at semi-rigid connected end is written as a linear function of rotational restraining stiffness and rotation of normal as (Wang et al 2000):

$$
M_{h 1}\left(z_{1}=\frac{L_{1}}{L}\right)=0,
$$

where $M_{h 1}\left(z_{1}=\frac{L_{1}}{L}\right)$ is the high-order moment for the first region.

Using Eq. (42), the position vectors at free and the fixed supported ends are transferred to the position vectors at the semi-rigid connected end by Eqs. (47) and (48), respectively. For the first model, the pile's end at the first region is semi-rigid connected and not restricted for horizontal displacement and the end at the third region is free as in figure 3a. For the second model, the pile's end at the first region is semi-rigid connected and restricted for horizontal displacement and the end at the third region is fixed supported as in figure $3 b$.

$$
\left\{\begin{array}{c}
w_{1}\left(z_{1}=\frac{L_{1}}{L}\right) \\
w_{1}^{\prime}\left(z_{1}=\frac{L_{1}}{L}\right) \\
\phi_{1}\left(z_{1}=\frac{L_{1}}{L}\right) \\
C_{\theta} \cdot w_{1}^{\prime}\left(z_{1}=\frac{L_{1}}{L}\right) \\
C_{\theta} \cdot \phi_{1}\left(z_{1}=\frac{L_{1}}{L}\right) \\
0
\end{array}\right\}=\left[\begin{array}{llllll}
F_{11} & F_{12} & F_{13} & F_{14} & F_{15} & F_{16} \\
F_{21} & F_{22} & F_{23} & F_{24} & F_{25} & F_{26} \\
F_{31} & F_{32} & F_{33} & F_{34} & F_{35} & F_{36} \\
F_{41} & F_{42} & F_{43} & F_{44} & F_{45} & F_{46} \\
F_{51} & F_{52} & F_{53} & F_{54} & F_{55} & F_{56} \\
F_{61} & F_{62} & F_{63} & F_{64} & F_{65} & F_{66}
\end{array}\right] \cdot\left\{\begin{array}{c}
w_{3}\left(z_{3}=0\right) \\
w_{3}^{\prime}\left(z_{3}=0\right) \\
\phi_{3}\left(z_{3}=0\right) \\
0 \\
0 \\
0
\end{array}\right\}
$$




$$
\left\{\begin{array}{c}
0 \\
w_{1}^{\prime}\left(z_{1}=\frac{L_{1}}{L}\right) \\
\phi_{1}\left(z_{1}=\frac{L_{1}}{L}\right) \\
C_{\theta} \cdot w_{1}^{\prime}\left(z_{1}=\frac{L_{1}}{L}\right) \\
C_{\theta} \cdot \phi_{1}\left(z_{1}=\frac{L_{1}}{L}\right) \\
Q_{1}\left(z_{1}=\frac{L_{1}}{L}\right)
\end{array}\right\}=\left[\begin{array}{llllll}
F_{11} & F_{12} & F_{13} & F_{14} & F_{15} & F_{16} \\
F_{21} & F_{22} & F_{23} & F_{24} & F_{25} & F_{26} \\
F_{31} & F_{32} & F_{33} & F_{34} & F_{35} & F_{36} \\
F_{41} & F_{42} & F_{43} & F_{44} & F_{45} & F_{46} \\
F_{51} & F_{52} & F_{53} & F_{54} & F_{55} & F_{56} \\
F_{61} & F_{62} & F_{63} & F_{64} & F_{65} & F_{66}
\end{array}\right] \cdot\left\{\begin{array}{c}
0 \\
0 \\
0 \\
M_{3}\left(z_{3}=0\right) \\
M_{h 3}\left(z_{3}=0\right) \\
Q_{3}\left(z_{3}=0\right)
\end{array}\right\}
$$

Eqs. (47) and (48) can be written in matrix form as:

$$
\begin{aligned}
& {\left[\begin{array}{lllccc}
F_{11} & F_{12} & F_{13} & -1 & 0 & 0 \\
F_{21} & F_{22} & F_{23} & 0 & -1 & 0 \\
F_{31} & F_{32} & F_{33} & 0 & 0 & -1 \\
F_{41} & F_{42} & F_{43} & 0 & -C_{\theta} & 0 \\
F_{51} & F_{52} & F_{53} & 0 & 0 & -C_{\theta} \\
F_{61} & F_{62} & F_{63} & 0 & 0 & 0
\end{array}\right] \cdot\left\{\begin{array}{c}
w_{3}\left(z_{3}=0\right) \\
w_{3}^{\prime}\left(z_{3}=0\right) \\
\phi_{3}\left(z_{3}=0\right) \\
w_{1}\left(z_{1}=\frac{L_{1}}{L}\right) \\
w_{1}^{\prime}\left(z_{1}=\frac{L_{1}}{L}\right) \\
\phi_{1}\left(z_{1}=\frac{L_{1}}{L}\right)
\end{array}\right\}=\left\{\begin{array}{l}
0 \\
0 \\
0 \\
0 \\
0 \\
0
\end{array}\right\}} \\
& {\left[\begin{array}{llllll}
F_{14} & F_{15} & F_{16} & 0 & 0 & 0 \\
F_{24} & F_{25} & F_{26} & -1 & 0 & 0 \\
F_{34} & F_{35} & F_{36} & 0 & -1 & 0 \\
F_{44} & F_{45} & F_{46} & -C_{\theta} & 0 & 0 \\
F_{54} & F_{55} & F_{56} & 0 & -C_{\theta} & 0 \\
F_{64} & F_{65} & F_{66} & 0 & 0 & -1
\end{array}\right] \cdot\left\{\begin{array}{c}
M_{3}\left(z_{3}=0\right) \\
M_{h 3}\left(z_{3}=0\right) \\
Q_{3}\left(z_{3}=0\right) \\
w_{1}^{\prime}\left(z_{1}=\frac{L_{1}}{L}\right) \\
\phi_{1}\left(z_{1}=\frac{L_{1}}{L}\right) \\
Q_{1}\left(z_{1}=\frac{L_{1}}{L}\right)
\end{array}\right\}=\left\{\begin{array}{l}
0 \\
0 \\
0 \\
0 \\
0 \\
0
\end{array}\right\} .}
\end{aligned}
$$

For non-trivial solutions of this problem, following relations are written by using Eqs. (49) and (50), as:

$$
\begin{aligned}
& \left|\begin{array}{llllcc}
F_{11} & F_{12} & F_{13} & -1 & 0 & 0 \\
F_{21} & F_{22} & F_{23} & 0 & -1 & 0 \\
F_{31} & F_{32} & F_{33} & 0 & 0 & -1 \\
F_{41} & F_{42} & F_{43} & 0 & -C_{\theta} & 0 \\
F_{51} & F_{52} & F_{53} & 0 & 0 & -C_{\theta} \\
F_{61} & F_{62} & F_{63} & 0 & 0 & 0
\end{array}\right|=0 \\
& \left|\begin{array}{llllcc}
F_{14} & F_{15} & F_{16} & 0 & 0 & 0 \\
F_{24} & F_{25} & F_{26} & -1 & 0 & 0 \\
F_{34} & F_{35} & F_{36} & 0 & -1 & 0 \\
F_{44} & F_{45} & F_{46} & -C_{\theta} & 0 & 0 \\
F_{54} & F_{55} & F_{56} & 0 & -C_{\theta} & 0 \\
F_{64} & F_{65} & F_{66} & 0 & 0 & -1
\end{array}\right|=0 .
\end{aligned}
$$




\section{Numerical analysis and discussions}

In this paper, for numerical analysis, two models that are partially embedded in Winkler soil and whose ends above the soil are semi-rigid connected by an elastic spring having the rotational spring rigidities of $C_{\theta}$, as one being not restricted for horizontal displacement and the other being restricted for horizontal displacement, respectively, are considered. For two examples, natural frequencies of the pile, $\omega_{i}(i=1,2,3)$ are calculated by using computer programs prepared by authors. Natural frequencies are found by determining values for which the determinant of the coefficient matrix is equal to zero. There are various methods for calculating the roots of the frequency equation. One commonly used and simple technique is the secant method in which a linear interpolation is employed. The eigenvalues, the natural frequencies, are determined by a trial and error method based on interpolation and the bisection approach. One such procedure consists of evaluating the determinant for a range of frequency values, $\omega_{i}$. When there is a change of sign between successive evaluations, there must be a root lying in this interval. The iterative computations are determined when the value of the determinant changed sign due to a change of $10^{-4}$ in the value of $\omega_{i}$.

For each example, $C_{S 1}=15000 \mathrm{kN} / \mathrm{m}^{3}$ and $C_{S 2}=60000 \mathrm{kN} / \mathrm{m}^{3}$. The length of the pile is taken as $15 \mathrm{~m}$ and $30 \mathrm{~m}$.

The all numerical results of this paper are obtained based on uniform, rectangular ReddyBickford and Timoshenko piles with the following data:

$$
\begin{aligned}
h & =0.50 \mathrm{~m} ; \quad b=0.30 \mathrm{~m} ; \quad E I_{x}=6.5625 \times 10^{3} \mathrm{kNm}{ }^{2} ; \\
A G & =121500 \mathrm{kN} ; \quad m=0.50 \mathrm{kN} \cdot \mathrm{sec}^{2} / \mathrm{m} ;
\end{aligned}
$$

for the axial force effect $N_{r}=0.25$ and 1.00 , fixity factors are taken as $f=0.25$ and $f=0.75$.

The all numerical results are given for the following three models: Timoshenko model with two values for shear correction factor $k$ and Reddy-Bickford model. Many values for the shear correction factor $k$ were suggested, but in this paper, the original values suggested by Timoshenko $k=\frac{5}{6}$ and $k=\frac{14}{17}$ are used (Gruttmann \& Wagner 2001).

Natural frequencies of the pile are obtained from the solution of Eqs. (51) and (52) according to the boundary conditions, by using the computer program for $N_{r}=0.25$ and $N_{r}=1.0$ with the values of $L, L_{1} / L, L_{2} / L$ and $L_{3} / L$ taken from table 1 .

For $L=15 \mathrm{~m}$, the frequency values obtained for the first three modes of Reddy-Bickford and Timoshenko piles whose end at the first region is semi-rigid connected and not restricted for horizontal displacement and the end at the third region is free are presented in table 2; for $L=30 \mathrm{~m}$, the frequency values obtained for the first three modes of the same piles are presented in table 3 being compared with the frequency values obtained for $N_{r}=0.25$ and $1 \cdot 00, f=0.25$ and 0.75 .

\begin{tabular}{|c|c|c|c|c|c|c|c|}
\hline$L_{1} / L=0.50$ & \multicolumn{2}{|c|}{$L_{2} / L=0.30$} & $L_{3} / L=0.20$ & \multicolumn{2}{|c|}{$L_{1} / L=0.50$} & $L_{2} / L=0.20$ & $L_{3} / L=0.30$ \\
\hline$L(m)$ & $L_{1}(m)$ & $L_{2}(m)$ & $L_{3}(m)$ & $L(m)$ & $L_{1}(m)$ & $L_{2}(m)$ & $L_{3}(m)$ \\
\hline 15 & $7 \cdot 5$ & $4 \cdot 5$ & $3 \cdot 0$ & 15 & $7 \cdot 5$ & $3 \cdot 0$ & $4 \cdot 5$ \\
\hline 30 & $15 \cdot 0$ & 9.0 & $6 \cdot 0$ & 30 & $15 \cdot 0$ & $6 \cdot 0$ & $9 \cdot 0$ \\
\hline
\end{tabular}

Table 1. Values of $L_{1}, L_{2}$ and $L_{3}$ with respect to values of $L, L_{1} / L, L_{2} / L$ and $L_{3} / L$. 


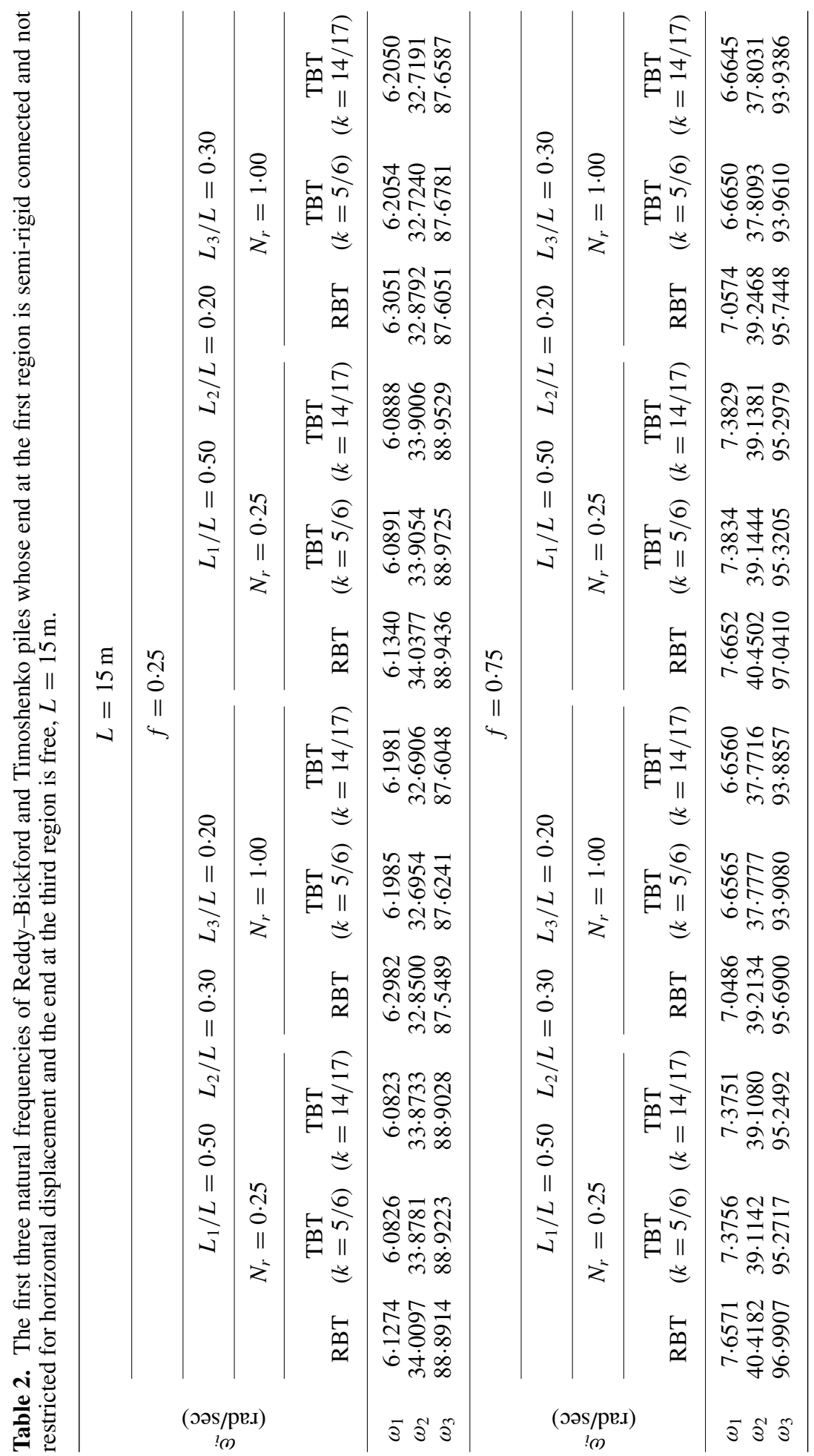




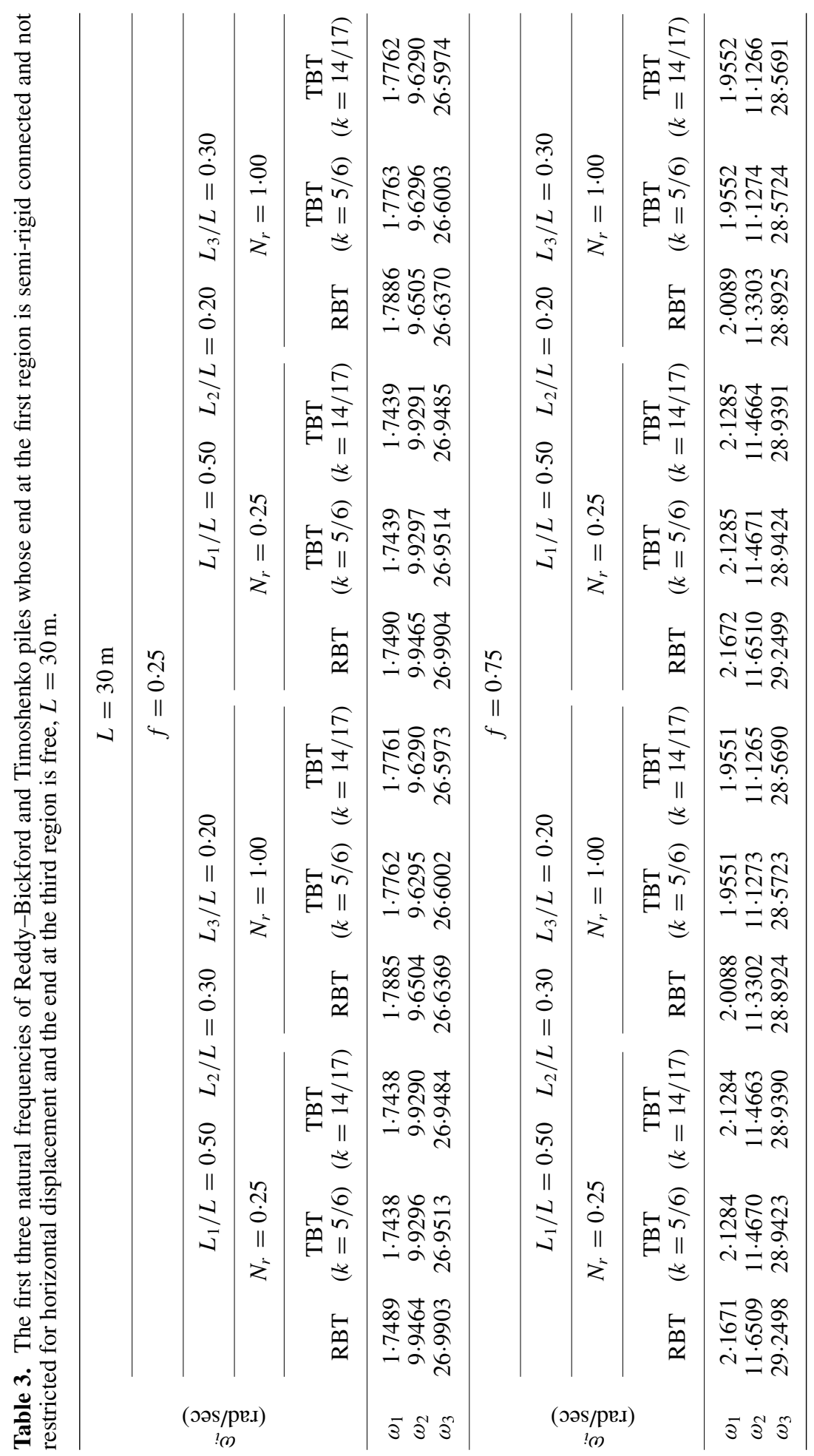


For $L=15 \mathrm{~m}$, the frequency values obtained for the first three modes of Reddy-Bickford and Timoshenko piles whose end at the first region is semi-rigid connected and restricted for horizontal displacement and the end at the third region is fixed supported are presented in table 4; for $L=30 \mathrm{~m}$, the frequency values obtained for the first three modes of the same piles are presented in table 5 being compared with the frequency values obtained for $N_{r}=0.25$ and $1.00, f=0.25$ and 0.75 .

The first two natural frequency values of Reddy-Bickford pile are higher than the first two natural frequency values of Timoshenko pile for both models and for all values of $N_{r}, L$ and $f$. For both models, the third natural frequency values of Reddy-Bickford pile are lower for $f=0.25$ and $L=15 \mathrm{~m}$; are higher for $f=0.75$ and $L=30 \mathrm{~m}$, than the third natural frequency values of Timoshenko pile. The third natural frequency values of Reddy-Bickford pile are higher than the third natural frequency values of Timoshenko pile for both models, $L=30 \mathrm{~m}$ and all values of $f$. The differences between Reddy-Bickford beam theory and Timoshenko beam theory are more prominent for the higher frequencies.

For all boundary conditions, the differences between natural frequency values of Timoshenko pile models with $k=\frac{5}{6}$ and $k=\frac{14}{17}$ are small.

For $f=0.25$ and for the condition of the other variables $\left(L, L_{1} / L, L_{2} / L\right.$ and $L_{3} / L$ ratios) are constant, as the axial compressive force acting to Reddy-Bickford pile and Timoshenko pile whose end at the first region is semi-rigid connected and not restricted for horizontal displacement and the end at the third region is free, is increased, the first natural frequency values of Reddy-Bickford pile and Timoshenko pile are increased but the second and the third natural frequency values are decreased. The natural frequency values of Reddy-Bickford pile and Timoshenko pile are decreased as the axial force is increased for $f=0.25$ in the second model and for $f=0.75$ at all boundary conditions. These results indicate that, the boundary conditions (especially the end at the third region) of Reddy-Bickford pile and Timoshenko pile are important for the effect of axial force.

As the total length of the pile is increased, a decrease is observed in natural frequency values for both beam theories; for all boundary conditions and the condition of the other variables ( $f, N_{r}, L_{1} / L, L_{2} / L$ and $L_{3} / L$ ratios) are being constant. This result indicates that the increase in the length of the pile leads to a reduction in natural frequency values for both beam theories.

A decrease is observed in natural frequency values of the first three modes of the pile for the condition of total pile length, $N_{r}$ and $L_{1} / L$ ratio being constant and of $L_{2} / L$ ratio being greater than $L_{3} / L$ ratio, for both support conditions and both beam theories. This decrease is more prominent for the short piles.

Natural frequencies values are different for two combinations of boundary conditions. For the condition of all variables are constant, the first three natural frequency values of the pile whose end at the first region is semi-rigid connected and restricted for horizontal displacement and the end at the third region is fixed supported are higher than the first three natural frequency values of the pile whose end at the first region is semi-rigid connected and not restricted for horizontal displacement and the end at the third region is free. This result indicates that the types of supporting affect the natural frequency values of the pile.

\section{Summary and conclusion}

In this study, starting from the governing differential equations of motion in free vibration, transfer matrices are developed by using Reddy-Bickford beam theory and the iterative- 


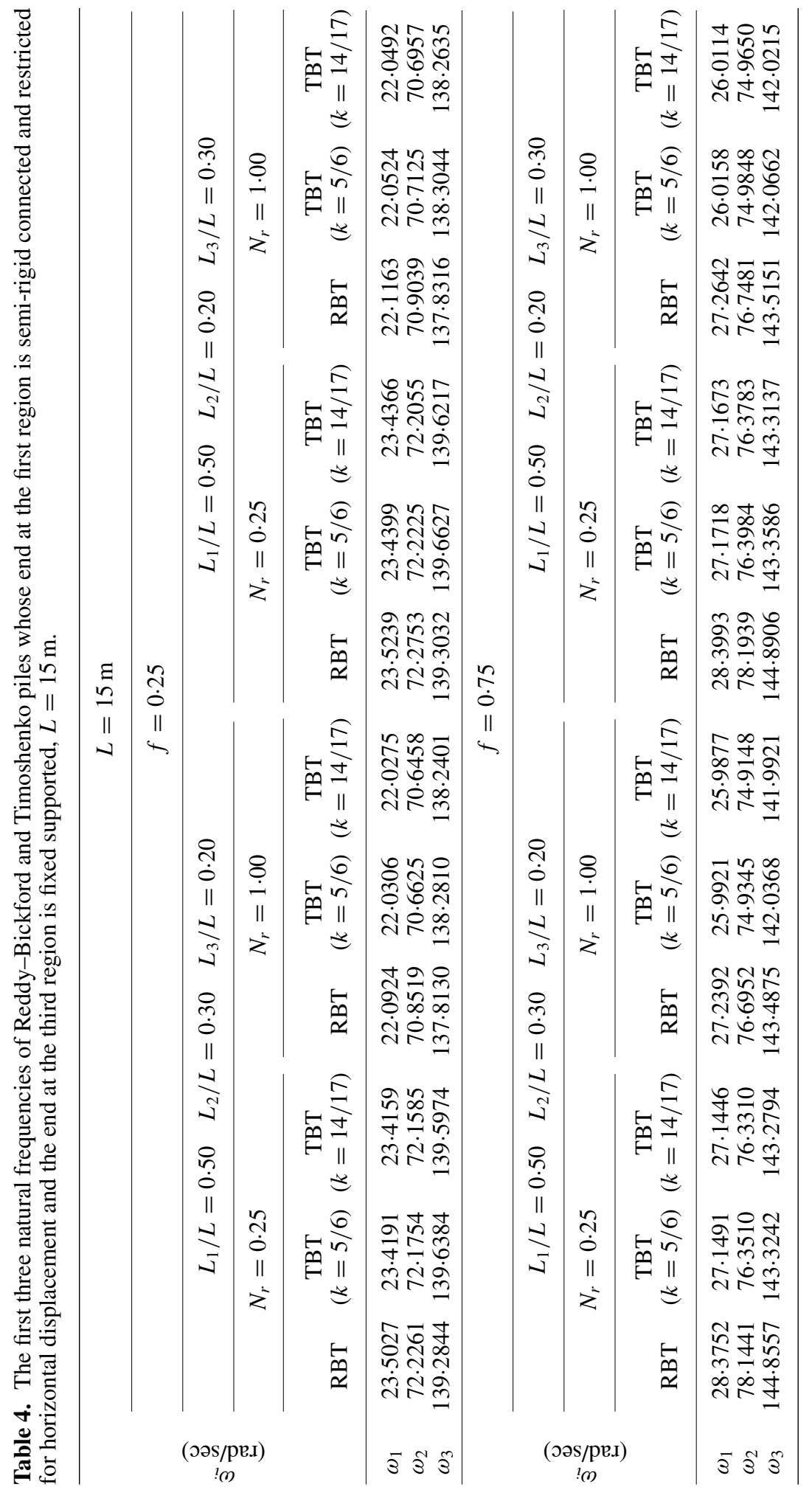




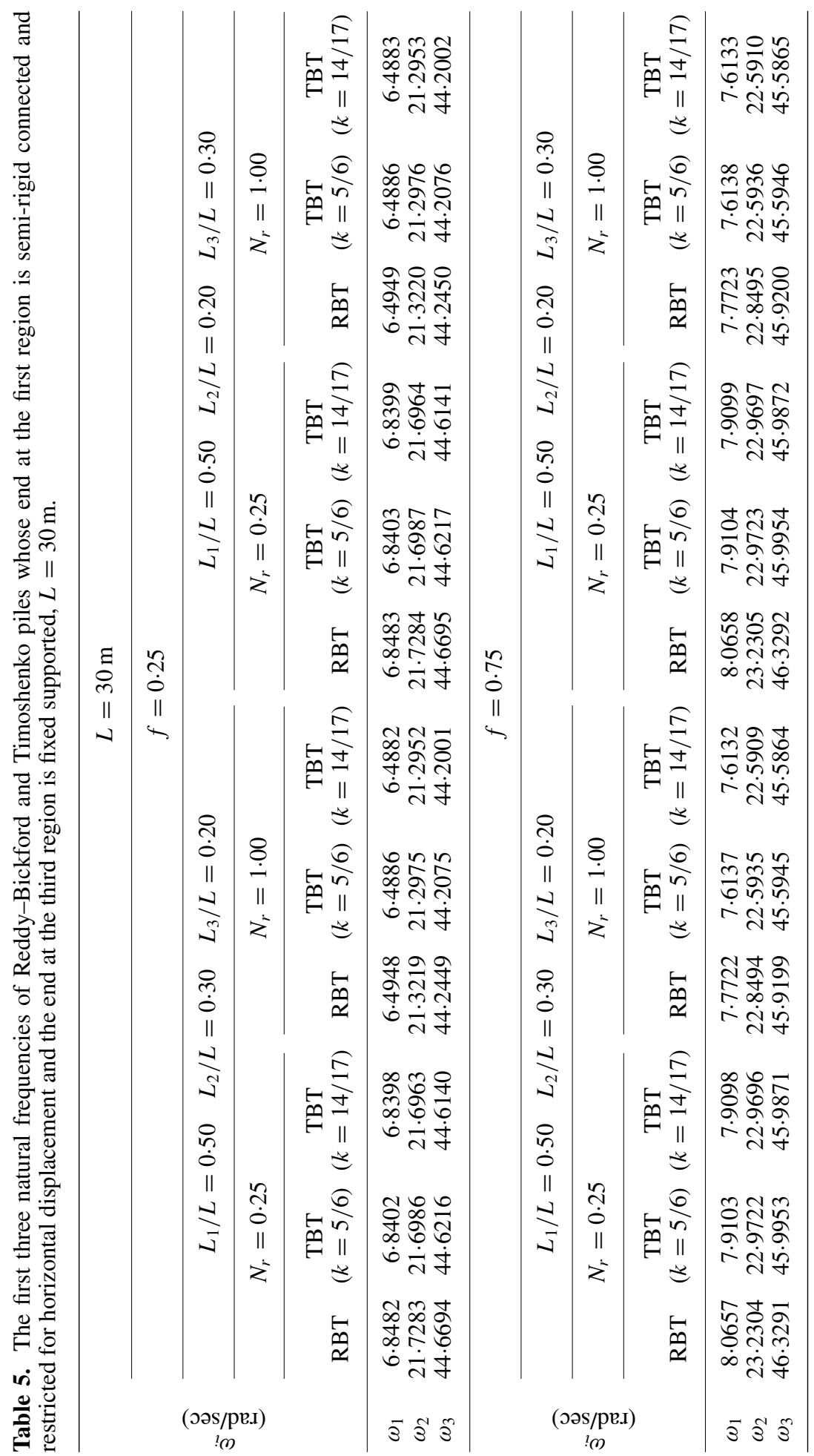


based computer programs are developed for solution of linear-homogeneous frequency equation set relating to free vibration of different supported two piles partially embedded in elastic soil. Variation in free vibration natural frequencies for the first three modes of the pile is investigated for $N_{r}=0.25$ and $N_{r}=1.0, f=0.25$ and $f=0.75$, due to supporting conditions of pile ends and different lengths of the pile. Natural frequency values obtained from Reddy-Bickford beam theory are compared with the results of Timoshenko beam theory. As shown, the differences between Reddy-Bickford beam theory and Timoshenko beam theory become more prominent for free vibration of piles embedded in elastic soil. So that, to be on safer side it is recommended to use the higher-order theory.

\section{Notation}

The following symbols are used in this paper.

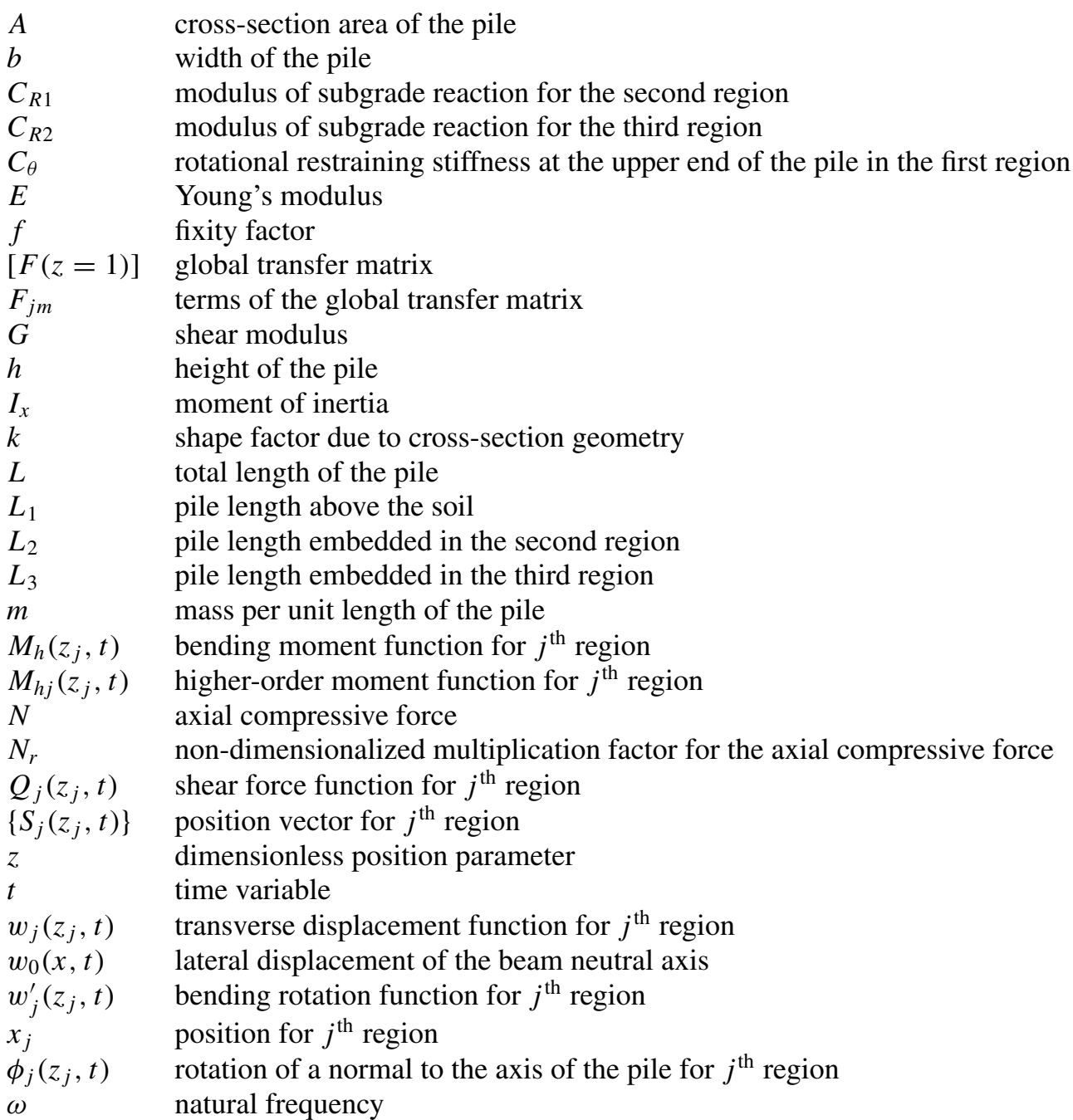




\section{References}

Aviles J, Sanchez-Sesma F 1983 Piles as barriers for elastic waves. J. Geotech. Eng. ASCE 109(GT9): $1133-1146$

Aviles J, Sanchez-Sesma F 1988 Foundation isolation from vibrations using piles and barriers. J. Eng. Mech. ASCE 114(11): 1854-1870

Boroomand B, Kaynia A M 1991 Vibration isolation by an array of piles. Soil Dyn. and Earthquake Eng. V, 683-691

Bickford W B 1982 A consistent higher order beam theory. Development in Theoretical and Appl. Mech. 11: 137-150

Catal H H 2002 Free vibration of partially supported piles with the effects of bending moment, axial and shear force. Eng. Struct. 24: 1615-1622

Catal H H 2006 Free vibration of semi-rigid connected and partially embedded piles with the effects of the bending moment, axial and shear force. Eng. Struct. 28: 1911-1918

Cowper G R 1966 The shear coefficient in Timoshenko's beam theory. J. Appl. Mech. 33(2): 335-340

Demirdag O, Catal H H 2007 Earthquake response of semi-rigid supported single storey frames modelled as continuous system. Struct. Eng. and Mech. 25(6): 767-770

Demirdag O 2008 Free vibration analysis of elastically supported Timoshenko columns with attached masses by transfer matrix and finite element methods. Sādhanā 33(1): 1-12

Doyle P F, Pavlovic M N 1982 Vibration of beams on partial elastic foundations. J. Earthquake Eng. and Struct. Dyn. 10: 663-674

Eisenberger M 2003 Dynamic stiffness vibration analysis using a high-order beam element. Int. J. Numerical Methods in Eng. 57: 1603-1614

Esmailzadeh E, Ohadi A R 2000 Vibration and stability analysis of non-uniform Timoshenko beams under axial and distributed tangential loads. J. Sound Vib. 236: 443-456

Gruttmann F, Wagner W 2001 Shear coefficient factors in Timoshenko's beam theory for arbitrary shaped cross-section. Computational Mech. 27: 199-207

Han S M, Benaroya H, Wei T 1999 Dynamics of transversely vibrating beams using four engineering theories. J. Sound Vib. 225: 935-988

Hetenyi M 1955 Beams on elastic foundations, $7^{\text {th }}$ edn., Michigan, The University of Michigan Press

Heyliger P R, Reddy J N 1988 A higher-order beam finite element for bending and vibration problems. J. Sound Vib. 126(2): 309-326

Levinson M 1981 A new rectangular beam theory. J. Sound Vib. 74: 81-87

Lin H P, Chang S C 2005 Free vibration analysis of multi-span beams with intermediate flexible constraints. J. Sound Vib. 281: 155-169

Liao S, Sangrey D A 1978 Use of piles as isolation barriers. J. Geotech. Eng. ASCE 104(GT9): 1139_ 1152

Monforton G R, Wu T S 1963 Matrix analysis of semi-rigid connected frames. J. Struct. Division, ASCE 89(6): 14-42

Murthy A V 1970 Vibration of short beams. AIAA 8: 34-38

Reddy J N 2002 Energy Principles and Variational Methods in Applied Mechanics, Second Edition, NY, John Wiley

Reddy J N 2007 Theory and Analysis of Elastic Plates and Shells, Second Edition, Philadelphia, PA, Taylor \& Francis

Timoshenko S P 1921 On the correction for shear of the differential equation for transverse vibrations of prismatic bars. Philos. Mag. 41: 744-746

Tuma J J, Cheng F Y 1983 Theory and Problems of Dynamic Structural Analysis, Schaum's Outline Series, New York: Mc Graw-Hill

Wang C M, Reddy J N, Lee K H 2000 Shear Deformable Beams and Plates: Relationships with Classical Solutions, The Netherlands, Elsevier Science Ltd.

West H H, Mafi M 1984 Eigenvalues for beam columns on elastic supports. J. Struct. Eng. 110(6): $1305-1320$ 
Yesilce Y, Catal H H 2008 Free vibration of piles embedded in soil having different modulus of subgrade reaction. Applied Mathematical Modelling 32: 889-900

Yokoyama T 1991 Vibrations of Timoshenko beam-columns on two parameter elastic foundations. Earthquake Eng. Struct. Dyn. 20: 355-370 